\title{
A LUTA DO NATIONAL UNION OF WOMEN TEACHERS PELA IGUALDADE DE GÊNERO
}

\author{
Amarilio Ferreira JR. ${ }^{1}$
}

\begin{abstract}
RESUMO: Este artigo tem como objetivo explicitar o processo de criação do NUWT pelas professoras feministas e sufragistas britânicas (inglesas e gaulesas). Movidas pela luta em defesa da igualdade remuneratória em relação aos professores, uma fração de professoras feministas militantes do National Union of Teachers (NUT) fundou, em 1904, a Equal Pay League (EPL). Depois, em 1906, a EPL adicionou à sua sigla a denominação National Federation of Women Teachers (EPL/NFWT) e, posteriormente, em 1920, a NFWT foi transformada no NUWT. A luta das professoras britânicas pela igualdade de salários entre homens e mulheres no âmbito da educação pública, conquistada somente em 1961, foi referência internacional para os movimentos feministas no mundo ocidental, principalmente na segunda metade do século XX.
\end{abstract}

Palavras-chave: Professoras feministas e sufragistas. Igualdade de gênero. National Union of Women Teachers (NUWT).

\section{THE STRUGGLE OF THE NATIONAL UNION OF WOMEN TEACHERS FOR GENDER EQUALITY}

\begin{abstract}
This article aims to explain the British (English and Gauls) feminist and suffragette teachers' process for creating the NUWT. Driven by the struggle for being equally paid in relation to male teachers, a fraction of militant feminist teachers from the National Union of Teachers (NUT) founded the Equal Pay League (EPL), in 1904. Then, in 1906, EPL added to its acronym the National Federation of Women Teachers (EPL/NFWT) and later, in 1920, NFWT was turned into NUWT. The struggle of British female teachers for equal pay between men and women in the field of public education, achieved only in 1961, was an international reference for feminist movements in the Western world, especially in the second half of the twentieth century.
\end{abstract}

Keywords: Feminist and suffragists teachers. Gender equality. National Union of Women Teachers (NUWT)

Este artigo é resultado do projeto de pesquisa, financiado pelo CNPq, intitulado: Trade Union Movement of Teachers in Brazil and Great Britain: A Comparative Study (1870-1990).

1. Universidade de São Carlos - Departamento de Educação - São Paulo (SP), Brasil. E-mail: ferreira@ufscar.br 


\title{
LA LUCHA DE NATIONAL UNION OF WOMEN TEACHERS POR LA IGUALDAD DE GÉNERO
}

\begin{abstract}
RESUMEN: Este artículo tiene como objetivo explicar el proceso de creación de NUWT por profesoras británicas (inglesas y galesas) feministas y sufragistas. Impulsada por la lucha por la igualdad salarial relativa a los docentes, una fracción de docentes militantes feministas del National Union of Teachers (NUT) fundó, en 1904, la Equal Pay League (EPL). Luego, en 1906, EPL agregó el nombre National Federation of Women Teachers (EPL/NFWT) a su acrónimo y, más tarde, en 1920, NFWT se transformó en NUWT. La lucha de las maestras británicas por la igualdad salarial entre hombres y mujeres en el campo de la educación pública, ganada solo en 1961, fue referencia internacional para los movimientos feministas en el mundo occidental, especialmente en la segunda mitad del siglo XX.
\end{abstract}

Palabras-clave: Profesoras feministas y sufragistas. Igualdad de género. National Union of Women Teachers (NUWT).

\section{Introdução}

A

produção deste artigo guarda relação direta com os vínculos institucionais mantidos pelo autor, desde 2011, com o Institute of Education (IoE) - inicialmente vinculado à University of London e, agora, à University College London (UCL) - mediante financiamentos da FAPESP e do CNPq. Durante esse período, o autor deste texto pesquisou, nos arquivos e na biblioteca da instituição, de forma intermitente, em três oportunidades: 2011-2012; 2014; e 2019². Em 2019, com o projeto de pesquisa "Movimento Sindical de Professores no Brasil e na Grã-Bretanha (Inglaterra e Gales): Um Estudo Comparado de 1870 a 1990", aprovado na modalidade Bolsa PQ do CNPq (2019-2022), o autor desenvolveu pesquisas nos arquivos do NUWT, que estão sob guarda do IoE.

O artigo em tela tem como escopo explicitar, para o campo educacional brasileiro, a maneira pela qual um pequeno grupo de professoras feministas e sufragistas fundou o NUWT nos primeiros decênios do século XX. Em língua portuguesa, as referências bibliográficas são ainda muito incipientes; mas, na tradição acadêmica anglo-saxônica, existe uma substantiva produção sobre o protagonismo sindical do NUWT no contexto da educação inglesa e gaulesa. A história do NUWT tornou-se referência, a partir da década de 1960, para a segunda onda do movimento feminista, tanto no Reino Unido quanto nos EUA. As fundadoras do NUWT travaram lutas reivindicatórias, desde 1904, organizadas com base nas seguintes demandas: igualdade remuneratória, organização sindical, sufrágio universal e sexualidade. Personagens de um enredo marcado por um cenário masculino e patriarcal, essas professoras inglesas e gaulesas sempre defenderam a completude das bandeiras que desfraldaram, pois, para elas, as condições materiais e espirituais de existência, no contexto britânico do início do século XX, dependiam da concretização - de forma orgânica e unitária - do conjunto dessas demandas.

A seguir, dá-se uma breve referência sobre os arquivos do NUWT que se encontram ao abrigo do IoE. Do ponto de vista cronológico, eles contêm uma extensa coleção de registros que se estendem de 1904 a 1961. As caixas incluem atas do Conselho Executivo e de várias comissões; relatórios de conferências; registros de filiadas; correspondências; recortes de jornais; folhetos; panfletos; cartazes e fotografias. Há também um conjunto de caixas sobre assuntos específicos: personagens históricas, organizações e campanhas que documentam a ampla gama de interesses que o sindicato defendia. Tais caixas incluem, por exemplo, 
documentos relativos às organizações de mulheres, como: o Six Point Group; o National Union for Societies for Equal Citizenship; a Women's Freedom League; o Open Door Council; e a Association of Women Clerks and Secretaries. Além disso, há fontes de outras entidades educacionais: English New Education Fellowship e Workers Educational Association. As caixas guardam também uma série de materiais biográficos concernentes a uma ampla gama de protagonistas que ajudaram a construir o NUWT.

De resto, todos os documentos, livros e artigos citados no presente texto foram traduzidos do inglês pelo autor.

\section{A Criação do NUWT}

A fundação do NUWT, em 1920, foi decorrência política direta do protagonismo exercido por um grupo de professoras ${ }^{2}$ que se identificavam por serem feministas ${ }^{3}$ e sufragistas ${ }^{4}$. Filiadas ao National Union of Teachers (NUT) ${ }^{5}$, fundado em 1870, elas militavam em defesa, fundamentalmente, de duas propostas: a) a igualdade salarial entre professores e professoras no âmbito das escolas estatais britânicas (Inglaterra e Gales); e b) o reconhecimento do direito de voto para as mulheres. Em ambas as pautas, as professoras feministas e sufragistas mantinham divergências com a posição hegemônica que prevalecia no sindicato, pois o NUT manifestava, na prática, uma política contrária a essas reivindicações (PIEROTTI, 1963, p. 9 e seguintes).

Contudo, o processo de fundação do NUWT remontava ao início do século XX. Em 1904, a tendência política representada pelas professoras feministas e sufragistas associadas ao NUT constituiu a Equal Pay League (EPL). Emily Phipps, em A history of the National Union of Women Teachers, relata que a iniciativa para a fundação da EPL partiu de uma articulação sindical entre o sr. Joseph B. Tate, um assistente de mestre em Birmingham, e a srta. L. E. Lane, diretora de uma escola primária em Londres (Holland Street School), durante a Conferência Anual que o NUT realizou na cidade de Portsmouth naquele mesmo ano (PHIPPS, 1928, p. 2 e seguintes) ${ }^{6}$.Os objetivos propostos pela EPL foram descritos pelos seus idealizadores da seguinte maneira:

\footnotetext{
A Equal Pay League foi formada no início de 1904, sob a presidência de F. C. Blackburn, presidente da Teachers' Provident Society [órgão do NUT]. Seu objetivo principal era melhorar as condições salariais e sociais das professoras por meio da imediata adoção, na Escala de Salários da National Union of Teachers, do princípio baseado na igualdade remuneratória entre professores e professoras. Pela primeira vez na história da National Union of Teachers, durante a realização da conferência em Portsmouth, a questão da desigualdade salarial existente foi discutida (HALL et al., 1909, p. 3 e seguintes).
}

Centrada na demanda sobre o pagamento igual para o trabalho de igual dimensão laboral, a EPL não foi uma articulação de caráter associativista exclusivamente constituída por professoras. As mulheres que participaram da sua criação, em 1904, entendiam que a luta sindical pela igualdade salarial entre professoras e professores "não deveria ser assumida como medida isolada, pois seria perigoso" (HALL et al., 1909, p. 3); ou seja, para elas, a Equal Pay não deveria ser tratada como reivindicação específica de professoras feministas e sufragistas. Para evitar o "perigo" representado pelo isolacionismo político-sindical no âmbito do NUT e ampliar a luta pela igualdade de gênero no âmbito da Escala Salarial, a articulação para a formação da sua primeira diretoria ficou assim constituída: 
Tabela 1. Primeira diretoria da Equal Pay League, eleita em 1904.

\begin{tabular}{cc}
\hline Presidente & $\begin{array}{c}\text { Sr. F. C. Blackburns } \\
\text { Presidente Financeiro e Memebro do Comitê de Assuntos Gerais do NUT } \\
\text { Presidente da Teachers' Provident Society }\end{array}$ \\
\hline Vice-presidente & $\begin{array}{c}\text { Srta. L. E. Lane } \\
\text { Diretora da Escola Holland Street, Blackfriars (London) }\end{array}$ \\
\hline Vice-presidente & $\begin{array}{c}\text { Srta. A. E. Hall } \\
\text { Diretora da Escola S. Albans Road (Dartford) }\end{array}$ \\
\hline Vice-presidente & $\begin{array}{c}\text { Sr. J. Baldwin } \\
\text { Secretário e } \\
\text { tesoureiro }\end{array}$ \\
\hline
\end{tabular}

Fonte: Phipps (1928, p. 3); Pierotti (1963, p. 2).

A EPL nascia, assim, com duas características distintivas: estava vinculada à organização sindical do NUT e, ao mesmo tempo, contava com a particiapção de três homens em cargos políticos importantes de sua estutura associativista: Blackburns, Baldwin e Tate ${ }^{7}$. Essa paradoxal composição entre professoras e professores na origem da Equal Pay, em que mulheres eram minoria, não lhe tirava o caráter de uma league identificada politicamente com os movimentos feministas e sufragistas (i. e., comprometida com as lutas das mulheres britânicas pela isonomia de direitos em relação aos homens, do ponto de vista tanto da cidadania plena quanto da profissional, por meio de salários iguais) ${ }^{8}$. Ao contrário, essa articulação de gêneros no âmbito do NUT ampliava a capacidade de difusão da principal questão sindical defendida pela EPL, qual seja: a iguadade salarial entre professoras e professores. Após sua constituição, a primeira tarefa política dessa diretoria foi produzir um relatório sobre as discussões que haviam sido travadas durante a Conferência Anual do NUT, realizada em Portsmouth. No "pequeno e modesto Report for 1904" - na definição de Pierotti (1963, p. 2) - encontramos a seguinte passagem:

A primeira resolução dos membros da League, no seu início, foi a de convencer os membros da Executiva do NUT a publicar, no Schoolmaster [jornal do NUT], os nomes de todos os associados que eram favoráveis ao salário igual entre homens e mulheres. A pesada despesa inicial foi justificada pelo aumento dos associados e pela impressão que se criou entre os oponentes da nossa proposta. Na Conferência de Portsmouth, a apresentação da plataforma com a nossa proposta foi feita mediante excelente discurso pronunciado por srta. A. E. Hall, Vice-presidente. Embora não tenhamos obtido sucesso, a minoria que votou pelo princípio do Equal Pay foi considerável e, por conseguinte, um passo importante foi dado por nosso Presidente sr. F. C. Blackburn, ao assegurar a adoção da proposta pelo NUT. A resolução da Executiva ficou assim:

"Class Mistresses [professoras] trabalhando em departamentos [escolas] mistos ou de meninos devem receber salários iguais aos Class Masters [professores] do mesmo departamento."

Isso agora aparece semanalmente no Schoolmaster, prefixado na Escala de Salários (EQUAL PAY LEAGUE, 1904, p. 1). 
Apesar da política baseada em um arranjo sindical que ia além da questão de gênero no interior da própria estrutura do NUT, a proposta de salários iguais, defendida pelo "excelente discurso pronunciado por srta. A. E. Hall”, não logrou êxito na Conferência de Portsmouth ${ }^{9}$. O revés indicava apenas o prelúdio da longa jornada de lutas que ainda seriam entabuladas em defesa da igualdade salarial entre professoras e professores. Contudo, nos anos que sucederam 1904, a EPL foi ampliando suas bases tanto na Inglaterra quanto em Gales. Logo, a league passou a contar com 73 associados - 68 mulheres e 5 homens -, distribuídos nas seguintes cidades: Aston, Bedford, Dartford, Derbyshire, Downham (Norfolk), Grimsby, Londres, Manchester, Redditch, Gales do Sul (Mountain Ash), Stoke-on-Trent, Stratford-on-Avon, Tunbridge, Birmingham e Coventry (EQUAL PAY LEAGUE, 1904, p. 3 e seguintes; PIEROTTI, 1963, p. 2).

Após a Conferência de Portsmonth, na qual a reivindicação por salários iguais havia sido derrotada, as professoras vinculadas à EPL passaram a demandar, por parte do NUT, que fosse colocada em prática uma política sindical objetivando os seguintos procedimentos: a) promover campanha de filiação das professoras ao NUT; b) estabelecer política de proporcionalidade entre homens e mulheres para as eleições dos delegados às Conferências Anuais; e c) incentivar eleição de mulheres para a direção executiva do sindicato (PHIPPS, 1928 , p. 4) ${ }^{10}$. Essas propostas, defendidas pela EPL, contudo, eram procrastinadas pelo NUT, pois, para o sindicato, a ampliação do poder de decisão reivindicada pelas professoras feministas e sufragistas significava que, com o tempo, suas demandas acabariam por ser aprovadas nas Conferências Anuais (p. ex., salários iguais e o engajamento na luta pela conquista do sufrágio universal $)^{11}$.

A renitência do NUT, todavia, não ficou sem resposta. Em 1906, dois anos depois de criação da EPL, as professoras feministas e sufragistas deram um passo à frente no processo que levaria, mais tarde, à ruptura definitiva com o próprio NUT: adicionaram ao nome da league a denominção embrionária do que viria a ser uma nova estrutura sindical: a National Federation of Women Teachers (NFWT), que ainda permaneceria organizada no interior do NUT (PHIPPS, 1928, p. 5; PIEROTTI, 1963, p. 2). Assim, a estruturação da EPL/NFWT ${ }^{12}$ permitiria o avanço da luta sindical das professoras feministas e sufragistas em dois sentidos complementares: o crescimento da adesão ao movimento pela igualdade de pagamentos (Inglaterra e Gales); e, ao mesmo tempo, a possibilidade de a NFWT ganhar autonomia associativa para encaminhar suas reivindicações sem, necessariamente, depender da estrutura sindical do NUT. Posteriormente, em 1909, a NFWT foi definitivamente consolidada como única estrutura associativista das professoras feministas e sufragistas para travar lutas econômicas e políticas. Emily Pierotti descreveu a criação da NFWT da seguinte maneira:

Logo após sua formação, a Equal Pay League acrescentou a designação "National Federation of Women Teachers" ao seu título. Nessa fase, no entanto, não havia dúvida: a National Federation estava transformando-se numa associação separada, como alternativa associativista ao NUT, e que oferecia aos seus membros os serviços completos de um sindicato. Além de apoiar a igualdade salarial entre professores homens e mulheres, passou a defender também que deveria haver "subvenções governamentais equivalentes per capita para as Girls' and Infants' Schools"; maior representação de professoras delegadas nas Conferências Anuais; e mais mulheres na Executiva do NUT. Contudo, não tratava a categoria dos professores como corpo totalmente “igualitário", pois também defendia que "a idade de aposentadoria das professoras deveria ser consideravelmente reduzida" (PIEROTTI, 1963, p. 2).

A Federation, portanto, "oferecia aos seus membros os serviços completos de um sindicato", mesmo levando em conta que o movimento das professoras feministas e sufragistas havia assumido, desde 1904, 
a tática da dupla filiação sindical: a professoras associavam-se tanto ao NUT quanto à EPL/FNWT. Essa dualidade sindical também garantia que as militantes feministas não ficassem isoladas nas regiões rurais, nas quais as concentrações de professoras eram pequenas. Notadamente, a luta contra as diferenças salariais entre professoras e professores, as quais eram mantidas, nos mesmos patamares, desde o início do século XX, ficaria cada vez mais exacerbada. No ano letivo de 1912-1913, por exemplo, a média salarial entre homens e mulheres que desenvolviam as mesmas atividades laborais nas escolas estatais britânicas estava assim configurada:

Tabela 2. Média salarial (Inglaterra e Gales) Ensino Fundamental (Higher Elementary School).

\begin{tabular}{cccc}
\hline Diretores de escolas & Professores & Diretoras de escolas & Professoras \\
$\mathfrak{E 2 7 2}$ & $£ 145$ & $£ 216$ & $£ 114$ \\
\hline
\end{tabular}

Fonte: Thompson (1927, p. 332) ${ }^{13}$.

Para além das lutas sindicais que reivindicavam a igualdade salarial e o direito de voto, o segundo decênio do século XX mergulhou os movimentos das feministas britânicas ${ }^{14}$ em um emaranhado de acontecimentos que podem ser assim sumariados: a) as manifestações de massas protagonizadas pelas mulheres em defesa da igualdade com os homens, principalmente em Londres ${ }^{15}$; b) a eclosão da Primeira Guerra Mundial (1914-1918); e c) a Revolução Russa (1917). Esses episódios - isolados e combinados produziram corolários contraditórios no seio das diversas tendências feministas britânicas: por um lado, elas se posicionaram contra as políticas de cortes nos valores dos salários e o aumento do custo de vida que fora gerado pelos gastos decorrentes da guerra ${ }^{16}$; por outro, defenderam o engajamento no esforço de guerra (indústria e saúde) e, ao mesmo tempo, saudaram as conquistas profissionais obtidas pelas mulheres na Rússia Soviética ${ }^{17}$.

Os impactos econômicos, sociais e políticos ocasionados pela Primeira Guerra Mundial aceleraram o processo de ruptura definitiva da NFWT com o NUT. No início do outono de 1919, a NFWT editava o primeiro número de seu jornal The Woman Teacher, que logo se transformaria em um dos principais instrumentos de luta pelos direitos iguais entre professoras e professores ${ }^{18}$. Em seguida, publicou-se, na quinta edição de The Woman Teacher, uma declaração de princípios com os propósitos que animariam as ações da NFWT em defesa das professoras inglesas e gaulesas:

A National Federation of Women Teachers acredita que os verdadeiros fins da educação não podem ser total e completamente alcançados até que as professoras tenham condições de trabalho e meios adequados de manifestação em questões educacionais. Para tanto, declara como seus os seguintes objetivos:

a. Recolher e representar as opiniões e os desejos de mulheres professoras e organizar e combinar suas ações.

b. Assegurar melhores pensões e aposentadoria opcional.

c. Garantir pagamento igual e incrementos iguais para homens e mulheres professores com o mesmo status profissional.

d. Garantir a manutenção de cada departamento de atendimento de meninas e bebês sob o controle das professoras.

e. Garantir a representação das mulheres nos âmbitos de todas as autoridades educacionais.

f. Assegurar representação efetiva e direta dos interesses das professoras no Parlamento. 
g. Garantir que todos os postos em níveis educacionais serão abertos igualmente aos homens e às mulheres e com remunerações iguais.

Se você aprova os objetos acima e não é ainda membro da NFWT, escreva para o secretário para mais detalhes ou para o nome e endereço do secretário local mais próximo (NATIONAL FEDERATION OF WOMEN TEACHERS, 1919).

Em 1920, logo após a divulgação desses objetivos, a Federation novamente cambiava sua designação sindical, passando a se chamar apenas National Union of Women Teachers (NUWT) ${ }^{19}$. O NUWT, uma vez constituído, adotou imediatamente a resolução que proibia a dupla filiação no âmbito da sua Executiva; ou seja, suas dirigentes não mais podiam ser filiadas ao NUT. Contudo, o NUWT levou tempo para pôr fim à adiada condição do conjunto de suas associadas; somente coibiu definitivamente a possibilidade da militância em ambos os sindicatos a partir de 1932 (PARTINGTON, 1976, p. 20; MANZER, 1970, p. 20).

\section{"Por que Deixei o NUT"}

O processo de consolidação do NUWT colocou fim à "unidade de ação sindical" que as professoras feministas e sufragistas haviam construído, entre 1904 e 1920, no interior do NUT. A ruptura com a mais importante estrutura sindical dos professores das escolas estatais inglesas e gaulesas, cuja origem remontava a $1870^{20}$, fora provocada pelas bandeiras de lutas que feministas e sufragistas haviam desfraudado em defesa da igualdade entre homens e mulheres desde o fim do século XIX. Elas partiam, portanto, do pressuposto de que a unidade sindical não mais poderia ser efetivada no âmbito de uma estrutura sindical "mista", na qual se manifestavam diferenças entre professores e professoras tanto em relação aos salários quanto nas questões relativas às oportunidades de trabalho (PHIPPS, 1928. p. 34).

A partir de 1920, a "unidade sindical", para as professoras feministas e sufragistas, seria concebível apenas entre pessoas que defendiam os mesmos objetivos. Portanto, a "unidade sindical" era considerada impossível entre aqueles situados em campos opostos; ou seja, professoras e professores filiados ao NUT. Com base nessa concepção de luta sindical, o rompimento assumiu a seguinte configuração: as defensoras dos salários iguais baseados exclusivamente no valor de cada trabalho realizado versus os partidários das diferenças salariais de acordo com o sexo. Para justificar a "nova política sindical", o NUWT publicou, no início dos anos 1920, uma pequena brochura que veiculava as versões das suas principais fundadoras e dirigentes a respeito dos motivos pelos quais elas haviam deixado o NUT. Os depoimentos, selecionados a seguir, são emblemáticos por explicitarem as principais causas que levaram à ruptura sindical promovida pelas professoras feministas e sufragistas:

1. A. G. Hewitt, ex-Presidente do NUWT e da East Ham (London; NUT), concedeu o seguinte testemunho:

Eu deixei o NUT quando finalmente me convenci de que as professoras não podiam encontrar um meio de expressão legítima por meio dessa organização. É um fato lamentável que a maioria dos professores ainda não reconheça que as opiniões e os votos de suas colegas mulheres valem tanto quanto os seus. Daí expressões familiares como: “Meeting 'packed' by women” ["Reunião 'lotada' de mulheres"]; "Swamped by the women's vote" ["Inundada pelo voto das mulheres"]. Então, veio a assinatura do Burnham Reports ${ }^{21}$ pelos representantes do NUT. Isso significava a 
traição ao princípio da "regra da maioria" [a vitória da igualdade salarial no referendo de 1919]. Como as mulheres faziam parte dessa maioria, essa traição é tolerada até pelos professores de espírito mais público. As professoras não podem tolerar tal conduta e manter seu respeito próprio (NATIONAL UNION OF WOMEN TEACHERS, [s. d.], p. 3).

2. Agnes Dawson, ex-Presidente do NUWT, explicou, de modo incisivo, os motivos que geraram a fratura:

Não foram apenas os acontecimentos de um único dia ou durante um único mês ou ano; mas fora gradualmente esclarecido, durante o transcorrer de muitos anos, que uma organização mista de professores - homens e mulheres - era insuportável para as mulheres que defendiam posições progressistas. Lembro-me bem da época em que, se uma mulher se arriscasse a se levantar em uma reunião para fazer um pronunciamento, havia gritos de "uma dama, sr. Presidente" e todos os outros oradores cediam as suas vezes para "uma dama" falar. Contudo, quando, mais tarde, os galanteadores descobriram que aquela mesma "dama" tinha pensamento próprio e estava tentando defender um caminho progressivo para as mulheres, [...] ela não era mais considerada uma dama e, muitas vezes, sequer era ouvida, nem antes, nem durante sua própria inscrição. Piadas grosseiras, à custa das mulheres, não eram incomuns, até que algumas das mais brilhantes mulheres sentiram-se demasiadamente mal para participar dos debates. [...] "Unity is strength" [“Unidade é força”] se tornou um slogan entre nós. Tínhamos esquecido o fato de que, embora estivéssemos no mesmo sindicato, não havia unidade entre nós. Algumas mulheres ficaram inquietas, mas a maioria de nós insistiu em acreditar que o certo era reivindicar, e era claro que venceríamos. Depois, vieram os miseráveis debates sobre o NUT War Aid Fund (Fundo do NUT para Auxílio à Guerra). Devemos esquecê-los? [...] As mulheres agora estavam começando a entender como os homens sempre venciam, mesmo quando eram derrotados nos debates; com eles, era um "jogo de cartas marcadas". [...] Eles, os homens, estavam de posse da maquinaria do sindicato e conheciam perfeitamente como suas engrenagens funcionavam. [...] As mulheres agora precisam se defender, devem provar que podem se organizar, que mulheres têm condições de planejar e podem ganhar ou perder em uma luta justa; que podem permanecer juntas. Só assim as mulheres serão capazes de aprender a confiar umas nas outras; só assim as mulheres conseguirão ganhar liberdade e igualdade. Hoje, não há dúvida quanto à sabedoria do passo que foi dado. O NUWT cresceu em número, popularidade e poder - e continua crescendo diariamente. A essência de sua força reside na adesão a seus princípios e no altruísmo de suas trabalhadoras (NATIONAL UNION OF WOMEN TEACHERS, [s. d.], p. 4-5).

3. Emily Phipps - ex-presidente da NFWT, editora do The Woman Teacher e ex-membro da Executiva do NUT (1914-1916) - vaticinou os seguintes argumentos:

Saí porque descobri que minha energia estava sendo desperdiçada. Os anos passados mediante presença assídua nas reuniões do NUT com objetivo de promover a aprovação da resolução do sufrágio, apesar da imensa preponderância de mulheres associadas ao NUT, não produziram absolutamente nenhum resultado, assim como os anos passados na tentativa de obter o Equal Pay, que havia sido aprovado no referendo ${ }^{22}$. Ainda que o ativismo do NUT tenha produzido, 
depois que muitas mulheres deixaram o sindicato, uma política acadêmica de acordo com o Equal Pay, nunca houve progresso em direção à sua efetiva realização. Seria muito melhor para nós se a resolução do Equal Pay nunca tivesse sido aprovada. A quantidade de energia gasta, por muitos anos, trabalhando no NUT para alcançar esses dois objetivos, contra uma minoria ativa e hostil nas Seções Locais, fez com que todas as tentativas das mulheres se transformassem em situações de abuso e recriminação. A quantidade de bens alcançados era totalmente desproporcional à quantidade de energia despendida. Mesmo quando conseguimos obter certo número de representantes na Executiva do sindicato, descobrimos que a Executiva só expressava a política e a plataforma do NUT. Uma mulher que defendia o sufrágio feminino, integrante da Executiva, disse, durante uma Conferência Anual, que nunca havia usado o dinheiro do NUT para defender o sufrágio feminino. É, exatamente, como deveria ser. No entanto, ela privou qualquer mulher que acreditasse na luta do sindicato em defesa do sufrágio feminino da oportunidade de ter sua opinião profissional influenciada a respeito dessa demanda. Assim, a posição da integrante da Executiva, alcançada com tanta dificuldade, apenas colocou nossas mulheres em uma posição falsa e gerou contra elas até mesmo a acusação de esconder suas verdadeiras opiniões em prol dos votos. Por esses motivos, defini que era melhor usar meu tempo e meu dinheiro trabalhando diretamente para as coisas que eu queria. Então, decidi me unir àquelas que queriam as mesmas coisas que eu defendia (NATIONAL UNION OF WOMEN TEACHERS, [s. d.], p. 6-7).

4. Alice M. Bale - membro da Executiva do NUWT e ex-Presidente do NUT (Cardiff/Gales) ofereceu a subsequente resposta para a questão:

Porque o NUT é inútil para as mulheres. Mais do que isso, sua influência é claramente hostil. Essa convicção, formada por testemunhar repetidas falhas em sucessivas Easter Conferences [Conferências Anuais do NUT], que deveriam tratar de maneira justa as questões das mulheres, foi se aprofundando e confirmada pela colossal falta de convicção das mulheres em continuarem na luta para colocar em prática o resultado do referendo sobre a igualdade de remuneração. [...] No entanto, apesar de sua Executiva ter homologado o resultado do referendo em favor do Equal Pay por sete votos contra três, o sindicato iniciou imediatamente as negociações salariais - Comitê Burnham - com base na antiga proposição ilegal e injusta. Após a instalação do Comitê Burnham, a desigualdade salarial foi incorporada pelo NUT. Um flagrante desrespeito à vontade do "rank and file" [trabalhador]; tal desrespeito ao sindicalismo seria difícil de encontrar paralelo. Se discordavam do resultado do referendo, o certo teria sido a renúncia e a convocação de eleições para se constituir uma nova Executiva. Posteriormente, a própria representação dos professores no Board of Education [Conselho de Educação] revelou, como se mais revelações fossem necessárias, que o grande obstáculo à realização do Equal Pay era o NUT. [...] Não devemos nós, que cuidamos dessa grande questão da igualdade das mulheres, gastar nosso tempo, nosso dinheiro e nossa influência pessoal na criação de nossa própria organização, tornando assim o NUWT - de jure bem como de fato - a voz oficial das professoras? Meu único arrependimento é não ter dado esse passo depois da Conferência de Aberystwyth (Gales), em 1911, quando, pela primeira vez, convenci-me de que o NUT era não apenas inútil para as mulheres, mas hostil (NATIONAL UNION OF WOMEN TEACHERS, [s. d.], p. 7-8). 
Esses depoimentos, concedidos pelas principais lideranças do NUWT, realçam que o ponto de inflexão que levou à definitiva ruptura com o NUT estava associado a dois episódios, vinculados diretamente à questão do Equal Pay. O primeiro relacionava-se diretamente ao referendo de 1919, no qual a proposta da igualdade salarial havia obtido votação majoritária, com quase 20 mil votos de diferença, em relação à política da permanência da diferença salarial entre professoras e professores (NATIONAL UNION OF WOMEN TEACHER, 1938. p. 3). Contudo, a proposta vencedora, que definia a igualdade salarial como plataforma programática do NUT, não foi levada "à sua efetiva realização" por parte da Executiva do sindicato. As professoras feministas e sufragistas haviam vencido o plebiscito da igualdade salarial por larga margem de votos, mas foram derrotadas pela política de discriminação do trabalho feminino, que prevalecia na máquina sindical do NUT.

O segundo episódio, decorrente do primeiro, foi a adesão do NUT à escala única de salários instituída pelo Comitê Burnham (1922), na qual continuava prevalecendo a desigualdade salarial entre professores e professoras. Mesmo com o resultado do referendo que aprovou a igualdade de salário, o NUT mantinha a recomendação para que suas respectivas bancadas de professores, nos painéis de negociações do Comitê Burnham, continuassem adotando a mesma política salarial anterior ao referendo de 1919²3.Daí, a convicção firmada por Alice M. Bale, membro da Executiva do NUWT, de que o NUT não era apenas um sindicato "inútil para as mulheres, mas hostil".

\section{Considerações Finais}

A cultura masculina dominante no interior do NUT, particularmente nos dois primeiros decênios do século XX, estava perpassada por um entendimento preconceituoso sobre as condições de gênero no exercício do magistério: considerava-se existir uma incompatibilidade entre trabalhar no ofício de ensinar e desempenhar plenamente os atributos inerentes à condição feminina, que eram exclusivamente resumidos ao casamento e aos cuidados com os filhos. Para os professores que controlavam politicamente a estrutura do poder sindical, apenas a mulher casada e mãe poderia garantir uma "vida normal" para a família; ou seja, transmitir os chamados "conhecimentos domésticos" considerados tradicionais para se "educar os filhos". Assim, o principal e mais antigo sindicato dos professores britânicos criava um impasse em relação às mulheres que optavam profissionalmente por serem professoras da escola estatal; além de relegar a segundo plano o fato de que as mulheres ganhavam menos que os homens pela realização do mesmo trabalho, defendia ainda a tese de que existiria um conflito entre ser, a um só tempo, professora e mãe. Por extensão, o sindicato aceitava as imposições estatais que proibiam as servidoras de cargos públicos de se casarem e, por conseguinte, tencionava ainda mais o pleno exercício da docência por parte das mulheres (KING, 1987, p. 35 e seguintes, JOYCE, 1987, p. 67 e seguintes; KEAN; ORAM, 1990. p. 155 e seguintes; LAWRENCE, 1994, p. 5-6.; WILSON, 2007, p. 670 e seguintes).

Por conta das demandas sociais reprimidas na centúria anterior, os dois primeiros decênios do século XX ficaram marcados, na Grã-Bretanha, pelas amplas manifestações e mobilizações públicas das mulheres por direitos iguais aos dos homens. Assim, as feministas e sindicalistas organizaram e lideraram as lutas por três relevantes questões sociopolíticas: direito ao sufrágio universal; direito de ocupar cargos públicos na condição de casadas; e salários iguais aos dos homens quando realizado o mesmo tipo de trabalho. Nascida nesse contexto, o NUWT ampliou as suas reivindicações, particularmente em decorrência do crescimento do gênero feminino no âmbito da categoria social do magistério primário ${ }^{24}$. Essas outras bandeiras desfraldadas pelo NUWT podem ser assim sumariadas: direito ao casamento para as professoras; direito à maternidade; 
instauração das leis de proteção familiar; abolição dos castigos corporais nas escolas; estabelecimento do número mínimo de alunos por salas de aula; política de formação de professores; ampliação da idade escolar para os jovens; extinção da pena de morte; instituição do salário mínimo; política de assistência à saúde; currículos que abordassem educação sexual, ciências domésticas para ambos os sexos e para crianças; e cinema nas escolas (PHIPPS, 1928, p. 30 e seguintes; NATIONAL UNION OF WOMEN TEACHERS, 1937 p. 1.; PIEROTTI, 1963, p. 20 e seguintes; KEAN; ORAM, 1990, p. 157).

Pressionado pelo contexto internacional engendrado pela Primeira Guerra Mundial, notadamente a Revolução Russa, e pelas mobilizações internas protagonizadas pelos movimentos sociais, o Parlamento Britânico tratou de implementar reformas institucionais que atendiam parte das demandas pleiteadas pelas feministas e sindicalistas. Diante disso, duas medidas foram adotadas imediatamente após a guerra:

a. Em 1918, o Parlamento Britânico aprovou o Representation of the People Act, lei que concedeu o direito de voto às mulheres com base em duas condições: idade mínima de 30 anos e comprovação de propriedade (moradia). Quanto aos homens, essa mesma lei definia que o voto teria idade mínima de 21 anos e não haveria quase nenhuma exigência referente à comprovação de propriedade. Mesmo com a manutenção da desigualdade política entre homens e mulheres, o movimento feminista e sindical saudou a aprovação da lei de 1918, pois possibilitou que a participação política feminina representasse 43\% (8,4 milhões votos) do eleitorado britânico (UNITED KINGDOM PARLIAMENT, 1918) ${ }^{25}$. As mulheres somente alcançaram igualdade política com os homens quando da aprovação, em 1928, do Representation of the People (Equal Franchise) Act (UNITED KINGDOM LEGISLATION, 1928); e

b. Em dezembro de 1919, as feministas obtiveram outra vitória: dessa vez, o Parlamento aprovou uma revisão no Sex Disqualification (Removal) Act: a emenda votada permitia que as mulheres pudessem ocupar, a partir de então, qualquer cargo no serviço público independentemente de serem casadas ou não (UNITED KINGDOM LEGISLATION, 1919).

O protagonismo das professoras feministas britânicas revelou, historicamente, que as relações existentes entre igualdade remuneratória, sindicalismo, sufrágio universal e sexualidade não eram questões desassociadas, mas interligadas no âmbito das vidas cotidianas, das experiências sociais e das consciências individuais, como as lutas feministas comprovariam a partir da segunda metade do século XX. Essas professoras nos legaram um aprendizado valioso, mas nem sempre praticado nas lutas imediatas: a construção gradativa e pacienciosa de uma estratégia vitoriosa. Ao longo de duas décadas, souberam dar passos planejados e medidos, sem exclusivismos; e atuaram com seus colegas homens, acumulando forças para que, no futuro, tivessem um sindicato que representasse apenas a elas e a suas principais demandas. Tais mulheres não viram em vida a concretização dos salários iguais, mas sua persistência continuou viva na geração que as sucedeu e, décadas mais tarde, materializou-se em política estatal. Portanto, olhando retrospectivamente, o caso do NUWT, nos mostra que, na história, nenhum processo começa do zero; é sempre continuidade das ações que nos antecedem. O grau de mudança ou de permanência dos elementos do passado dependerá sempre, como vimos, da correlação de forças no processo que está em curso. A mudança pode demorar, mas é um elemento intrínseco da história, e as fundadoras do NUWT souberam construir a mudança mesmo quando momentaneamente tiveram que retroceder.

As mulheres que fundaram o NUWT, na saga das lutas que se arrastavam desde a segunda metade do século XIX, consciente e explicitamente sempre se definiram como seres políticos e feministas. Seu feminismo era uma síntese de múltiplas determinações engendradas pelas condições materiais e subjetivas 
de existência no contexto de uma sociedade marcada profundamente pela dominação masculina. Eram professoras que enfrentavam discriminação em termos de remuneração e oportunidades de emprego e estavam impedidas, como cidadãs, de exercerem qualquer participação, mesmo que nominalmente, no âmbito da denominada "democracia parlamentar". Muitas dessas mulheres foram atraídas para a militância no interior do NUWT por causa das suas experiências anteriores nos movimentos de defesa do sufrágio universal. A decisão de ingressar no NUWT representava, para muitas militantes feministas, uma distinção que marcaria suas trajetórias - como mulheres e como professoras - por todas as suas vidas. Para elas, o NUWT sempre foi uma organização feminista e, ao mesmo tempo, um sindicato.

\section{Notas}

1. O autor deste artigo foi Visiting Fellow no Department of Humanities and Social Sciences da Faculty of Policy and Society, sob a supervisão do Professor Gary McCulloch, durante os dois primeiros vínculos institucionais mantidos pelo autor com IoE.

2. Entre as professoras que articularam e organizaram o processo de fundação do NUWT, podemos destacar as seguintes: Ethel Elizabeth Froud (1880-1941); Emily Frost Phipps (1865-1943); Teresa Billington-Greig (1877-1964); Agnes Dawson (18731953); Nancy Stewart Parnell (1901-1975); Grace Cottell (1891-?); Beatrice M. Pearson (?-1958); Alice Amelia Kenyon (?-?); Lizzie Cutten (1888-1920); Theodora Ellen Bonwick (1876-1928); Florence E. Key (1887-?). Para uma compreensão mais abrangente com relação ao protagonismo das chamadas "mulheres feministas do NUWT", dignos de nota são Phipps (1928, p. 1 e seguintes), Pierotti (1963, p. 1 e seguintes), Partington (1976, p. 10) e King (1987, p. 31 e seguintes).

3. As radicalizações políticas protagonizadas pelas militantes feministas, em defesa do sufrágio universal tiveram como uma de suas consequências "o encarceramento de centenas de suffragettes, muitas das quais fizeram greve de fome como forma de protesto. Receando a morte de algumas delas e a consequente produção de mártires, o governo adotou a 'alimentação forçada', feita por meio de um tubo enfiado boca adentro - processo bárbaro, visto como tortura. Muitas suffragettes foram assim alimentadas durante semanas, em média três vezes por dia. Kitty Marion, atriz famosa, por exemplo, foi submetida à alimentação forçada mais de 230 vezes. Todavia, só a partir do momento em que as suffragettes adotaram essas formas de luta é que a campanha pelo direito de voto feminino na Grã-Bretanha começou a ser levada a sério pelos políticos e pela imprensa” (ABREU, 2002, p. 464).

4. Sobre o protagonismo sufragista das professoras que criaram o NUWT, consultar Law (1997, p. 52 e seguintes).

5. No início do século XX, o NUT tinha 42 mil associados: 22 mil professores e 20 mil professoras, distribuídos em 430 Associações Locais (NOCK; WING, 1900, p. 3).

6. Segundo Miss L. E. Lene, o encontro paralelo à Conferência de Portsmouth, que decidiu pela criação da EPL, contou com a participação de 30 professoras (THE VICTORY DINNER, 1928, p. 2).

7. Miss L. E. Lane, no "Report for 1904”, referiu-se ao trabalho desempenhado por Joseph B. Tate na secretaria da EPL da seguinte maneira: "nosso secretário, o Sr. Joseph B. Tate, provou ser simplesmente inestimável. Sem sua assistência e seus conselhos, não teríamos realizado, certamente, o progresso que alcançamos. Ele fez um trabalho incansável, zeloso e incessante sob as circunstâncias mais desalentadoras. Não temos o desejo de fazer comparações ofensivas, mas, se a Equal Pay League pudesse ser comparada a uma embarcação, deveríamos estar inclinados a atribuir ao sr. Jos. B. Tate a parte da hélice de parafuso, sem a qual, é claro, mesmo o navio mais poderoso se torna inútil” (EQUAL PAY LEAGUE, 1904, p. 2).

8. A respeito das ligações unitárias e solidárias entre as organizações das mulheres feministas e sufragistas britânicas em defesa das igualdades civis e profissionais em relação aos homens, durante as primeiras décadas do século XX, consultar Law (1997).

9. Emily Phipps, em A history of the National Union of Women Teachers, afirma que a proposta baseada no salário igual entre professoras e professores foi derrotada "por uma larga maioria" de votos (PHIPPS, 1928, p. 4).

10. Em 1909, a Executiva do NUT era composta por 35 integrantes efetivos, sendo apenas dois deles mulheres (JOYCE, 1987, p. 67).

11. Com relação à recusa do NUT em se engajar na campanha sufragista defendida pelas mulheres feministas, examinar Phipps (1928, p. 6).

12. Emily Phipps relata também que apenas Joseph Tate continuou como secretário da EPL após a criação da NFWT, ou seja, EPL/ NFWT acabaram por promover uma espécie de "depuração" na ala masculina que dava apoio ao movimento das mulheres feministas e sufragistas (PHIPPS, 1928, p. 5).

13. Uma ampla panorâmica a respeito da desigualdade salarial entre professores e professoras ingleses e gauleses pode ser encontrada em Gosden (1972, p. 21 e seguintes), Partington (1976, p. 8 e seguintes) e Seifert (1987, p. 36). 
14. Na primeira metade do século XX, além da NFWT e do NUWT, as principais organizações feministas e sufragistas britânicas foram as seguintes: National Federation of Women Workers (1874); National Federation of Women's Institutes (1897); National Health Society (1908); National Industrial and Professional Women's Suffrage Society; National Labour Women's League (1880); National Society for Women's Suffrage (1876); National Union of Societies for Equal Citizenship (1919); National Union of Women's Suffrage Societies (1870); and National Women Citizens' Association (1913) (GORDON; DOUGHAM, 2001, p. 95 e seguintes).

15. Sobre as manifestações do NUWT em defesa do Equal Pay logo após a Primeira Guerra Mundial, ver Seifert (1987, p. 61).

16. As posições assumidas pelo movimento sindical dos professores britânicos em relação às consequências econômicas e sociais geradas pela Primeira Guerra Mundial podem ser encontradas em Lawn (1996, p. 65).

17. A respeito das influências exercidas pelas ideias socialistas no âmbito do movimento sindical dos professores britânicos, durante o segundo decênio do século XX, consultar Lawn (1996, p. 92) e Seifert (1987, p. 36).

18. Importante referência a respeito do papel que The Woman Teacher desempenhou na consolidação sindical do NUWT encontra-se em Phipps (1928, p. 54-55).

19. A Conferência de fundação do NUWT ocorreu na cidade de Bath (Inglaterra). Em 1922, o NUWT já possuía um total de 8.500 filiações, situadas em 122 organizações municipais na Inglaterra e de Gales (KEAN; ORAM, 1990. p. 156.).

20. Com relação ao protagonismo sindical do NUT entre 1870 e 1970, examinar Bourne e MacArthur (1970).

21. Os salários dos professores ingleses e gauleses eram, desde 1902, determinados no interior de cada uma das Local Education Authorities (LEA) existentes. Essa forma de definição salarial vinha produzindo discrepâncias e, ao mesmo tempo, provocava concorrências nos âmbitos das políticas salariais adotadas pelas LEA. Em 1919, foi instituída a escala única de salários, por meio do Burnham Reports. A Escala Burnham, como ficou conhecida, recebeu essa designação em homenagem a Lord Burnham (1862-1933), seu primeiro presidente. Posteriormente, o Comitê Burnham ficou encarregado não só de estabelecer a escala salarial dos professores das escolas primárias, mas também dos professores das escolas secundárias. O Painel de Professores, instituído pelo Comitê Burnham (1921), era inteiramente composto por representantes do NUT (UNITED KINGDOM LEGISLATION, 1916-1987; PARTINGTON, 1976, p. 8).

22. Em decorrência da pressão exercida pela NFWT, o NUT se viu obrigado a convocar, em 1919, um referendo sobre a igualdade salarial entre professores e professoras. A pergunta formulada para a mencionada consulta foi a seguinte: "Você é a favor de remuneração igual para professoras e professoras com o mesmo status profissional?" Os resultados obtidos foram os que se seguem: 35.004 a favor; 15.039 contra. A partir de então, a igualdade salarial entre professores e professoras passou a ser política oficial do NUT, embora tenha, historicamente, postergado a luta pela paridade salarial entre professores e professoras ingleses e gauleses. A conquista da renumeração igual somente seria conquistada décadas depois, em 1961 (PIEROTTI, 1963, p. 17).

23. A respeito das consequências geradas pelo fato de o NUT não ter encaminhado a proposta da igualdade salarial entre professores e professoras após o referendo de 1919, verificar Seifert (1987, p. 60 e seguintes).

24. Em 1911, a composição da categoria profissional dos professores (Inglaterra e Gales) tinha a seguinte configuração: Professores: 68.670; Professoras: 183.298; Total: 251.968 (GOSDEN, 1972, p. 2). O grande contingente de professoras estava alocado nas escolas primárias e infantis, enquanto as escolas secundárias eram "territórios pedagógicos" exclusivos do gênero masculino.

25. Depois da aprovação da lei, o total do eleitorado britânico saltou de oito para 21 milhões (UNITED KINGDOM PARLIAMENT, 1918).

\section{Referências}

ABREU, Z. Luta das mulheres pelo direito de voto: Movimentos sufragistas na Grã-Bretanha e nos Estados Unidos. Arquipélago - História, 2a Série, VI, 2002. p. 443-469.

BOURNE, R.; MACARTHUR, B. The struggle for education (1870-1970): A pictorial history of popular education and the National Union of Teachers. London: Schoolmaster Publishing Company, 1970.

EQUAL PAY LEAGUE. Report for 1904. Birmingham, 1904.

GORDON, P.; DOUGHAN, D. Dictionary of British Women's Organizations (1825-1960). London/New York: Routledge, 2001. 
GOSDEN, P. H. J. H. The evolution of a profession: A study of the contribution of teachers' associations to the development of school teaching as a professional occupation. Oxford: Basil Blackwell, 1972.

HALL, A. E. et al. Equal Pay League and National Federation of Women Teachers, 1909.

KEAN, H.; ORAM, A. "Men must be educated and women must do it": The National Federation (later Union) of Women Teachers and contemporary feminism 1910-30. Gender and Education, v. 2, n. 2, p. 147-167, 1990.

KING, S. Feminists in teaching: The National Union of Women Teachers, 1920-1940. In: LAWN, M.; GRECE, G. (orgs.). Teachers: The culture and politics of work. London: New York/Philadelphia: The Flamer Press, p. 31-49, 1987.

JOYCE, M. Being a feminist teacher. In: LAWN, M.; GRECE, G. (orgs.). Teachers: The culture and politics of work. London: New York/Philadelphia: The Flamer Press, p. 67-89, 1987.

LAW, C. Suffrage and power: The women's movement (1918-1928). London/New York: I. B. Tauris Publishers, 1997.

LAWN, M. Modern Times? Work, professionalism and citizenship in teaching. London: The Falmer Press, 1996.

LAWRENCE, E. Gender and trade unions. London: Taylor \& Francis, 1994.

MANZER, R. A. Teachers and politics: The role of the National Union of Teachers in the making of national educational policy in England and Wales since 1944. Manchester: University of Manchester at the University Press, 1970.

NATIONAL FEDERATION OF WOMEN TEACHERS. Objects. The Woman Teacher: The organ of the National Union of Women Teachers, v. I, n. 5, p. 33, Oct. 241919.

NATIONAL UNION OF WOMEN TEACHERS. Why I left the NUT. London, [s. d] early 1920s.

NATIONAL UNION OF WOMEN TEACHERS. Another victory: The removal of the Marriage Bar. London, 1935. (Pamphlet).

NATIONAL UNION OF WOMEN TEACHERS. The history of the women teachers' demand for equal pay. London, 1938. (Pamphlet).

NOCK, C.; WING, C. T. National Union of Teachers and the work it does. Portsmouth: NUT, 1900.

PARTINGTON, G. Women teachers in the 20th century in England e Wales. Windsor: NFER Publishing Company Ltd., 1976.

PHIPPS, E. F. A history of the National Union of Women Teachers. London: NUWT, 1928.

PIEROTTI, A. M. The story of the National Union of Women Teachers. Southend-on-Sea: NUWT, 1963.

SEIFERT, R. V. Teacher militancy: A history of teacher strikes (1896-1987). London/New York: The Falmer Press, 1987.

THE VICTORY DINNER. The Woman Teacher: The organ of the National Union of Women Teachers, v. X, n. I, p. 2, Oct. 51928.

THOMPSON, D. F. Professional solidarity among the teachers of England. New York: Columbia University Press, 1927. 
UNITED KINGDOM PARLIAMENT. Representation of the People Act, 1918. Disponível em: http:// www.parliament.uk/about/living-heritage/transformingsociety/electionsvoting/womenvote/case-study-theright-to-vote/the-right-to-vote/birmingham-and-the-equal-franchise/1918-representation-of-the-peopleact/1918-representation-of-the-people-act-first-page/. Acesso em: 20 nov. 2019.

UNITED KINGDOM LEGISLATION. The National Archives. Records of the Salaries Branch and Burnham Committees, 1916-1987. Disponível em: http://discovery.nationalarchives.gov.uk/details/r/C822. Acesso em: 20 nov. 2019.

UNITED KINGDOM LEGISLATION. Sex Disqualification (Removal) Act, 1919. Disponível em: http:// www.legislation.gov.uk/ukpga/Geo5/9-10/71. Acesso em: 20 nov. 2019.

UNITED KINGDOM LEGISLATION. Representation of the People (Equal Franchise) Act, 1928. Disponível em: http://www.parliament.uk/about/living-heritage/transformingsociety/electionsvoting/womenvote/casestudy-the-right-to-vote/the-right-to-vote/birmingham-and-the-equal-franchise/1928-equal-franchise-act/. Acesso em: 20 nov. 2019.

WILSON, D. S. Fighting the 'damnable triumph' of feminism: battles between teachers' unions in interwar Britain. Gender and Education, v. 19, n. 6, p. 669-676, Nov. 2007. https://doi.org/10.1080/09540250701650581

\section{Sobre o Autor}

Amarilio Ferreira Jr. é Professor Titular do Departamento de Educação da Universidade Federal de São Carlos (UFSCar). Realizou doutorado em História Social pela Universidade de São Paulo (USP) e estágio de pós-doutorado em História da Educação no Institute of Education (IoE) da University of London (Bolsa FAPESP). É bolsista de produtividade em pesquisa do CNPq e credenciado no Programa de Pós-Graduação em Educação da UFSCar (mestrado e doutorado), com ênfase em História, Filosofia e Sociologia da Educação.

Recebido: 13 nov. 2019

Aceito: 28 abr. 2020 